\title{
RÉGIMEN JURÍDICO DE LA POLICÍA LOCAL DE MELILLA
}

\author{
Antonio Jesús García Alemany \\ Técnico de Administración General \\ Profesor Tutor de Derecho Administrativo del Centro UNED Melilla \\ antgarcia@melilla.uned.es
}

\begin{abstract}
"En memoria de mi abuelo Antonio Alemany Mariné, fefe de la Policía municipal de Melilla (1969-1978)"
\end{abstract}

Resumen: El artículo realiza un estudio del sistema de fuentes jurídicas aplicables actualmente al Cuerpo de Policía Local de la Ciudad de Melilla, haciendo especial referencia a las particularidades que tras la aprobación de la Ley Orgánica 2/1995 de 13 de marzo que aprueba el Estatuto de Autonomía de Melilla inciden en su régimen jurídico. El autor pretende ayudar a conocer la dificultosa aplicación legislativa y reglamentaria que conforman el ordenamiento regulador de este instituto armado de naturaleza civil resaltando la potestad reglamentaria que cuenta la Ciudad para configurar su estatuto policial fundamentalmente derivada, además del propio Estatuto de Autonomía, de la aprobación del Estatuto Básico del Empleado Público.

Palabras Clave: Régimen Furídico, Policía Local, Fuerzas y Cuerpos de seguridad, Ciudad de Melilla, potestad reglamentaria.

Abstract: The article makes a study of the system of legal sources currently applicable to the Local Police Corps of the City of Melilla, making special reference to the particularities that after the approval of the Organic Law 2/1995 of March 13 approving the Statute of Autonomy of Melilla affect its legal regime. The author intends to help know the difficult legislative and regulatory application that make up the regulatory order of this armed institute of civil nature highlighting the regulatory power that the City has to configure its fundamentally derived police statute, in addition to the Statute of Autonomy itself, the approval of the Basic Statute of the Public Employee.

Keywords: Legal Regime, Local Police, Security Forces and Bodies, City of Melilla, regulatory authority. 
Podemos definir al Cuerpo de Policía Local de la Ciudad de Melilla como un Instituto armado de naturaleza civil, perteneciente a las Fuerzas y Cuerpos de Seguridad configuradas conforme a la Constitución de 1978 (CE), de estructura y organización jerarquizada ${ }^{1}$ bajo la superior autoridad del Presidente de la Ciudad y, en su caso, del Consejero de Seguridad Ciudadana ${ }^{2}$, cuyas funciones específicas se desarrollan, fundamentalmente, dentro de su territorio municipal ${ }^{3}$. Analizar su régimen jurídico requiere considerar el orden constitucional y estatutario de distribución de competencias entre el Estado y la Ciudad junto al principio formal de jerarquía normativa, lo que nos trasladará en primer lugar a la propia $\mathrm{CE}$ atendiendo a la misión trascendental que se encomienda a todas las Fuerzas y Cuerpos de Seguridad ${ }^{4}$ de protección del libre ejercicio de los derechos y libertades que son objeto de su Título I, y en última instancia a los reglamentos aprobados por la propia Ciudad a tenor de la potestad reglamentaria que le otorga, en materia de policía local, la Ley Orgánica 2/1995 de 13 de marzo que aprueba el Estatuto de Autonomía de Melilla (EA).

Partiendo de la norma constitucional, el artículo 104 de la CE prescribe la regulación de las Fuerzas y Cuerpos de Seguridad, estableciendo su cometido fundamental y reservando a ley orgánica determinadas materias de su régimen: "1. Las Fuerzas y Cuerpos de Seguridad, bajo la dependencia del Gobierno, tendrán como misión proteger el libre ejercicio de los derechos y libertades y garantizar la seguridad ciudadana. 2. Una ley orgánica determinará las funciones, principios básicos de actuación y estatutos de las Fuerzas y Cuerpos de Seguridad." La precitada reserva de ley orgánica se resalta expresamente, además, en la propia CE en su artículo 149.1.29 que atribuye, de forma exclusiva, la competencia legislativa sobre seguridad pública al Estado, sin perjuicio de la "posibilidad de creación de policías por las Comunidades Autónomas en la forma que se establezca en los respectivos Estatutos en el marco de lo que disponga una

Artículo 52.1 de la LOFCS.

2 Artículo 3.1 del Reglamento de la Policía Local de la Ciudad Autónoma de Melilla (BOME $n^{\circ} 5472$ de 25 de agosto de 2017).

3 Pueden actuar fuera de su territorio en situaciones de emergencia y previo requerimiento de las autoridades competentes o cuando ejerza actuaciones de protección de autoridades en los términos habilitados por el ordenamiento jurídico de conformidad con los arts. 51.3 de la LOFCS y 5 del RPLM.

$4 \quad$ Artículo 2 de la LOFCS: "Son Fuerzas y Cuerpos de Seguridad: a) Las Fuerzas y Cuerpos de Seguridad del Estado dependientes del Gobierno de la Nación. b) Los Cuerpos de Policía dependientes de las Comunidades Autónomas. c) Los Cuerpos de Policía dependientes de las Corporaciones Locales". 
ley orgánica" y el artículo 148.1.22 que limita las posibles competencias autonómicas sobre policías locales a lo que "establezca una ley orgánica"5.

Por tanto, la CE cede a una ley orgánica el diseño de las líneas esenciales del régimen jurídico de las Fuerzas y Cuerpos de Seguridad, en su conjunto, tanto de las dependientes del Gobierno de la Nación como de las Policías Autonómicas y Locales6, debiendo establecer los principios básicos de actuación comunes y fijando sus criterios estatutarios fundamentales. Esta premisa atiende a que el concepto de Fuerzas y Cuerpos de Seguridad utilizado por el legislador es un concepto genérico que engloba todos aquellos cuerpos policiales existentes en el territorio nacional con independencia de la Administración Pública de la que dependan de forma inmediata.

En la Ciudad de Melilla, esta remisión en materia de policía local a una norma legislativa específica se resalta en el artículo 21.1.24 del EA que le atribuye competencia en materia de "Policía local en los términos que establezca la Ley a que se refiere el artículo 149.1.29 de la Constitución", lo que supone reconocerle facultades en este ámbito pero supeditándose a una ley concreta, la Ley Orgánica 2/1986 de 13 de marzo, de Fuerzas y Cuerpos de Seguridad del Estado (LOFCS), como reguladora de la competencia exclusiva estatal en materia de seguridad pública que va a condicionar el ejercicio de la competencia de la Ciudad sobre policía local y, en consecuencia, va a actuar como parámetro de su validez.

La prevalencia de la LOFCS se reitera en el ordenamiento jurídico estatal aplicable al Cuerpo de Policía Local de Melilla en dos ámbitos legales fundamentalmente:

1. Por una lado, en la legislación estatal básica de función pública, el artículo 3.2 del Real Decreto Legislativo 5/2015, de 30 de Octubre, que aprueba el Texto Refundido de la Ley del Estatuto Básico del Empleado Público (TREBEP), aplicable a la Ciudad de Melilla en virtud de su artículo 2.1 en relación con la Disposición Adicional Tercera, dispone que "Los Cuerpos de Policía Local se rigen también por este Estatuto ..., excepto en lo establecido para ellos en la Ley Orgánica 2/1986, de 13 de marzo, de Fuerzas y Cuerpos de Seguridad".

Implícitamente y respecto a la policía judicial, el carácter de Ley Orgánica se deduce del contenido del artículo 126 de la CE.

6 En el supuesto de la Ciudad de Melilla, su Policía propia tienen el carácter de "local" como expresamente determina el Estatuto de Autonomía en su artículo 21.1.24. 
2. Por otro, en la legislación estatal de régimen local, de aplicación a Melilla por la remisión que realiza los artículos 30 y 31 de su Estatuto de Autonomía, que reproduce la referencia priorita de la LOFCS en materia de policía local. Así, la Ley 7/1985, de 2 de abril, reguladora de las Bases de Régimen Local (LBRL) en su Disposición final Tercera establece que "El personal de las Policías Municipales y de los Cuerpos de Bomberos gozará de un Estatuto específico, aprobado reglamentariamente, teniendo en cuenta respecto de los primeros la Ley de Fuerzas y Cuerpos de Seguridad del Estado". Igualmente, el Real Decreto Legislativo 781/1986 de 18 de abril, que aprueba el Texto Refundido de Disposiciones legales vigentes en materia de Régimen Local, en su artículo 173 impone que la Policía Local "ejercerá sus funciones de acuerdo con lo previsto en el Título V de la Ley Orgánica de Fuerzas y Cuerpos de Seguridad".

De esta manera, tras la CE, el cuerpo legislativo fundamental de la Policía Local de Melilla es la LOFCS, que da cumplimiento al mandato de reserva a ley orgánica impuesto por el texto constitucional, integrando, junto a la Constitución y el Estatuto de Autonomía, el conjunto normativo de valoración de las regulaciones que, respecto a esta materia, dicten posteriormente tanto el Estado como la propia Ciudad. Así el Tribunal Constitucional en su Sentencia del 21 de enero de $1993^{7}$ señaló que la LOFCS "en efecto concreta los diferentes Cuerpos y Fuerzas de Seguridad en un planteamiento territorial pero también sectorial, puesto que no olvida la policía judicial, determina sus funciones respectivas, proclama los principios de su actuación, marca las bases del estatuto personal de sus agentes y configura tanto orgánica como funcionalmente el principio de coordinación en los distintos niveles. En consecuencia, esta Ley Orgánica forma parte del grupo normativo que ha de ser utilizado para apreciar la conformidad o disconformidad con la Constitución de los dos preceptos impugnados ...”, reconociéndole el carácter de ley cabecera básica del sistema jurídico de la Policía Local ${ }^{8}$.

\footnotetext{
STC 25/1993, Recurso 1753/1998.

La primacía de la LOFCS en el sistema normativo de la Policía Local de Melilla fue reconocida, contundentemente, por la Sentencia 1884/2012 (Rec. 1362/2011) del Tribunal Supremo de 16 de marzo de 2012 al pronunciarse sobre las funciones asumidas por la figura de los Agentes de movilidad concluyendo que "se ha creado por el Reglamento un nuevo cuerpo de funcionarios, auxiliar de la Policía, sin tener una habilitación legal para ello y contradiciendo lo dispuesto en el artículo 53.3 de la Ley Orgánica 2/1986 de 13 de marzo...".
} 
Respecto a su estructura, la LOFCS cuenta, actualmente, con un Preámbulo, cinco Títulos, 54 artículos, cuatro disposiciones transitorias, cuatro adicionales, cinco finales y una derogatoria siendo aplicable específicamente a las Policías Locales, además de las disposiciones estatutarias comunes y principios básicos de actuación del conjunto de Fuerzas y Cuerpos de Seguridad, el Título V (artículos 51 a 54).

Como dijo Villagómez Cebrián (1997, p. 128) la LOFCS es "la Ley policial general que se configura como el marco normativo fundamental en la organización, funciones y actividad de la Policía Municipal en materia de seguridad pública, a la que naturalmente, se le aplica el régimen jurídico de la actividad de la policía de seguridad". En sentido similar se pronuncian refiriéndose a la Policía local, entre otros, Castell Arteche (1989, p. 223-227) al señalar que "la ley de Fuerzas y Cuerpos de Seguridad se constituía en el eje esencial para este tipo de policía" y Pérez Luque (1999, p. 368) que al estudiar el régimen jurídico aplicable a este Cuerpo destaca que "Resalta en este bloque normativo la Ley Orgánica 2/1986, que es la primera ley a aplicar a esta policía en materia de seguridad pública".

Siguiendo con el sistema de fuentes, el artículo 52.1 de la LOFCS define a los Cuerpos de Policía Local como Institutos armados de naturaleza civil con estructura y organización jerarquizada, señalando que su régimen estatutario se rige por:

-Los principios generales de los capítulos II y III del título I que recogen las Disposiciones estatutarias comunes aplicables a todas las Fuerzas y Cuerpos de Seguridad y el Título V, arts. 51 a 549, todo ello con la adecuación que exija la dependencia de la Administración correspondiente.

-Las disposiciones dictadas al respecto por las Comunidades Autónomas.

-Los Reglamentos específicos para cada Cuerpo y demás normas dictadas por los correspondientes Ayuntamientos.

9 Con la salvedad que la sección $4 .^{a}$ del capitulo IV del título II que regulaba el régimen disciplinario ya no se encuentra en vigor al haberse derogado por la Ley Orgánica 4/2010 de 20 de mayo, del Régimen disciplinario del Cuerpo Nacional de Policía que es de aplicación a los policías locales a tenor de su Disposición final sexta "La presente Ley Orgánica se aplicará a los Cuerpos de Policía Local de acuerdo con lo previsto en la legislación orgánica reguladora de las Fuerzas y Cuerpos de Seguridad. 
El orden de prelación establecido por el precepto referido constituye, según el propio Tribunal Supremo en su Sentencia de 7 de julio de $1997^{10}$, "la norma base rectora de los Cuerpos de Policía Local" al determinar la normativa aplicable. El carácter de "norma rectora" que le otorga al artículo 52.1 de la LOFCS el Tribunal Supremo es adecuado en la medida que difícilmente a través de una única Ley Orgánica se puede regular el conjunto normativo de la Policía Local requiriendo la colaboración de otras disposiciones ya que en esta materia se entrelazan las competencias legislativas y reglamentarias del Estado con las potestades normativas de las Comunidades Autónomas, Ciudades con Estatutos de Autonomía como Ceuta y Melilla o Entidades Locales.

En el sistema normativo de la Policía Local de Melilla, tras los preceptos aplicables de la $\mathrm{LOFCS}^{11}$, hay que remarcar la inoperatividad en el ámbito territorial de la Ciudad de la referencia que realiza el artículo 52.1 de la LOFCS a las "disposiciones dictadas por las Comunidades Autónomas". Y es que el artículo 148.1.22 de la CE posibilita que las CCAA puedan asumir las competencias en materia de "coordinación y demás facultades en relación con las policías locales en los términos que establezca una ley orgánica", habilitando que a través de sus respectivas leyes de coordinación puedan homogeneizar y homologar los cuerpos de Policía Local de manera que se permita una prestación de servicios en idénticas condiciones en los diferentes municipios de la respectiva CCAA y se determinen criterios uniformes de formación, organización, dotación y actuación policial. Esta facultad autonómica no puede ser asumida en el ámbito de la Ciudad atendiendo a dos motivos fundamentales:

1) El artículo 21.1.24 de su Estatuto de Autonomía no reconoce expresamente la facultad de coordinación respecto a la Policía Local de la Ciudad en los términos expresos que establece el artículo 148.1.22 de la CE, atendiendo a que difícilmente puede hablarse de "coordinación y demás facultades en relación con las policías locales..." cuando nos encontramos ante un Cuerpo único que

STS 4803/1997 (Recurso 9354/1995).

Es necesario resaltar que, junto a la LOFCS, tiene incidencia en la materia otras leyes orgánicas, destacándose actualmente la Ley Orgánica 6/1985, de 1 de julio, del Poder Fudicial, la Ley Orgánica 4/2015, de 30 de marzo, de Protección de la Seguridad Ciudadana dictada de conformidad con lo dispuesto en los artículos 149.1.29 y 104 de la CE y la Ley Orgánica 4/2010, de 20 de mayo, del Régimen disciplinario del Cuerpo Nacional de Policía. 
ejerce sus funciones de manera singular en el territorio municipal de la Ciudad ${ }^{12}$. De hecho, la coordinación ${ }^{13}$ es un concepto que usa la Constitución como instrumento para la fijación de medios y sistemas de relación, con objeto de lograr una cierta homogeneidad y hacer posible, en su caso, actuaciones conjuntas y de colaboración mutua entre las policías locales de los diferentes municipios de la correspondiente Comunidad Autónoma, lo que carece de eficacia en el ámbito territorial de la Ciudad establecido por el Estatuto de Autonomía, que no queda, obviamente, integrada en Comunidad Autónoma alguna.

2) Si bien, la Constitución Española admite en su Disposición Transitoria Quinta la posibilidad de que la Ciudad de Melilla se constituyera en Comunidad Autónoma si así lo decidía el respectivo Ayuntamiento, por mayoría absoluta de sus miembros y lo autorizaran las Cortes Generales mediante Ley Orgánica; la vía utilizada para aprobar la Ley Orgánica 2/1995 de 13 de Marzo que aprobó el Estatuto de Autonomía fue la opción otorgada por el constituyente en el artículo 144 b) ${ }^{14}$ que permitía las Cortes Generales acordar un Estatuto de Autonomía para territorios no integrados en la organización provincial sin necesidad de contar con la voluntad territorial. La utilización de esta segunda alternativa ha supuesto que la indefinición de la Ciudad no fuera resuelta plenamente, a mi juicio, con la aprobación del Estatuto de Autonomía de Melilla pues si bien el debate sobre la naturaleza jurídica de la Ciudad se ha mantenido fundamentalmente en el ámbito doctrinal, es cierto que en el terreno de aplicación práctica tanto el Tribunal Constituciona ${ }^{15}$ como el Tribunal Supremo ${ }^{16}$ han coincidido en entender que las Ciudades con Estatuto no pueden ser consideradas Comunidades Autónomas sino entidades locales con autonomías reforzadas, respecto al régimen general del resto de municipios, y derivadas de sus propios Estatutos de Autonomía,

12 De conformidad con el artículo 2 del E.A de Melilla: "El territorio de la Ciudad de Melilla es el comprendido en la delimitación actual de su territorio municipal".

13 STC 32/1983 de 28 de abril de 1983, Rec. 94/1982.

14 Preámbulo del E.A de Melilla: "El presente Estatuto de Autonomía, establecido de acuerdo con lo previsto en el artículo 144 b) de la Constitución Española, es la expresión juridica de la identidad de la ciudad de Melilla y define sus instituciones, competencias y recursos, dentro de la más amplia solidaridad entre todos los pueblos de España."

15 Autos 201 y 202 de 2000 y Sentencia 240/2006.

16 Sentencia de 23 de diciembre de 2004. 
lo que nos impide atribuirle el carácter de CCAA que le habilite a asumir las facultades de coordinación de las policías locales que, recordemos, se han llevado a cabo en virtud de diferente normas de rango legal conocidas como leyes de coordinación careciendo, además, la Asamblea de la Ciudad de Melilla de la correspondiente potestad legislativa.

Por lo anterior, en un segundo escalón y dentro del marco de la LOFCS, la Policía Local de Melilla debe someterse a la legislación estatal de régimen local por remisión de los artículos $1.3^{17}, 51.1^{18} \mathrm{y}$ $52.1^{19}$ de la LOFCS y los artículos $30^{20}$ y $31^{21}$ de su Estatuto de Autonomía (EA), sin perjuicio, eso sí, de las especialidades organizativas y de funcionamiento respecto a, fundamentalmente, sus instituciones de autogobierno. Y es que los miembros de la Policía Local de Melilla conforman una clase de funcionarios con unas características propias que los relacionan, pero al mismo tiempo los diferencian de otros servidores públicos, pues por un lado, son policías, siéndoles de aplicación normas propias de los Cuerpos y Fuerzas de Seguridad, y, por otro, son funcionarios de la Administración de la Ciudad Autónoma por lo que se les aplica el régimen jurídico local a tenor del propio Estatuto.

Así, el Título III del Estatuto de Autonomía establece los principios legales esenciales a los que se ha de sujetar la actividad jurídica de la Ciudad, siendo de particular trascendencia lo dispuesto en el artículo 30 según el cual su régimen jurídico se rige "con carácter general por la legislación del Estado sobre Régimen Local, sin perjuicio de las especialidades

17 Artículo 1.3 de la LOFCS: "Las Corporaciones Locales participarán en el mantenimiento de la seguridad pública en los términos establecidos en la Ley Reguladora de las Bases de Régimen Local y en el marco de esta Ley".

18 Artículo 51.1 de la LOFC: "Los municipios podrán crear cuerpos de policía propios, de acuerdo con lo previsto en la presente ley, en la Ley de Bases de Régimen Local y en la legislación autonómica".

19 Se aplica la LOFCS a las Policías Locales "con adecuación que exija la dependencia de la Administración correspondiente".

20 Artículo 30 del E.A: "La ciudad de Melilla se rige en materia de procedimiento administrativo, contratos, concesiones expropiaciones, responsabilidad patrimonial, régimen de bienes y demás aspectos del régimen jurídico de su Administración, por lo establecido con carácter general por la legislación del Estado sobre Régimen Local, sin perjuicio de las especialidades derivadas de la organización propia de la Ciudad establecidas por el presente Estatuto".

$21 \quad$ Artículo 31 del E.A: "El régimen jurídico del personal de la ciudad de Melilla será por lo que se refiere al personal propio, el establecido en la legislación estatal sobre función pública local". 
derivadas de la organización propia de la Ciudad establecidas por el presente Estatuto". Esta remisión a la normativa local se produce en otros preceptos del Estatuto como en el artículo 31 que, en cuanto al régimen del personal propio, se remite "a lo establecido en la legislación sobre función pública local". De lo anterior resulta que el régimen jurídico de la Ciudad es, fundamentalmente y por así establecerlo su propio Estatuto, el recogido en legislación estatal de régimen local en coherencia con el artículo 149.1.18 de la Constitución que reserva al Estado la competencia exclusiva sobre "Las bases del régimen jurídico de las Administraciones públicas" y la ausencia de capacidad para dictar leyes de la Asamblea melillense, reconociéndose la posibilidad de, sobre la base local, adaptar reglamentariamente las especialidades de la organización particular establecida en su Estatuto de Autonomía.

De esta manera, el Cuerpo de Policía Local de Melilla debe someterse tras la LOFCS, sin perjuicio de las especialidades derivadas de la organización propia de la Ciudad, por las normas estatales de aplicación vigentes en materia de régimen local, que esencialmente son, con rango legal, la Ley 7/1985, de 2 de abril, reguladora de las Bases de Régimen Local (LBRL) y el Real Decreto legislativo 781/1986, de 18 de abril, por el que se aprueba el Texto Refundido de las Disposiciones legales vigentes en materia de Régimen Local (TRRL) aunque es cierto que, son pocas las referencias específicas que realizan ambas normas de forma concreta a la Policía Local ${ }^{22}$. Hay que recordar en este aspecto que la Sentencia 14/2013 del Tribunal Constitucional de 31 de enero de 2013 ha resaltado que el concepto de "legislación "abarca también, en sentido amplio y antiformalista, las normas reglamentarias ${ }^{23}$, por lo que la referencia en la remisión del E.A a "lo establecido con carácter general por la legislación del Estado sobre Régimen Local" debe entenderse tanto a las normas legales como reglamentarias de régimen local.

Además del conjunto normativo anterior y por la condición de funcionarios que ostentan los miembros de la Policía Local en Melilla, la legislación sobre función pública local aplicable en virtud del artículo 31

\footnotetext{
22 Por su trascendencia sobre el régimen jurídico de la Ciudad de Melilla, hay que mencionar también la Ley 27/2013, de 27 de diciembre de Racionalización y Sostenibilidad de la Administración Local.

23 En este punto debemos recordar que desde la STC 18/1982, de 4 de mayo, se viene considerando que la competencia estatal de "legislación» ha de entenderse en sentido material, refiriéndose no sólo a la ley en sentido formal, sino también a los reglamentos ejecutivos e, incluso, a las circulares, si tienen naturaleza normativa.
} 
del E.A debe complementarse con el TREBEP cuyo artículo 3.2 incluye expresamente a los Cuerpos de Policía Local dentro de su ámbito de aplicación $^{24}$ estableciendo una diferenciación en la aplicación de esta Ley a las Policías Locales respecto al resto de Fuerzas y Cuerpos de Seguridad a los cuales sólo se les aplicará el TREBEP cuando así lo disponga su legislación específica ${ }^{25}$ sin perjuicio de su correspondiente aplicación supletoria $^{26}$. Lo anterior acredita, a mi juicio, una deficiente técnica legislativa pues el excluir el TREBEP en su articulo $4 \mathrm{e}$ a las Fuerzas y Cuerpos de Seguridad de su ámbito de aplicación y no especificar en el propio precepto el régimen particular de la Policía Local, podría dar a entender a sensu contrario que no forma parte de estos Cuerpos de Seguridad, lo que contravendría frontalmente el artículo 2 de la LOFCS.

La aplicación en Melilla del TREBEP se reconoce expresamente en su artículo $2.1^{27} \mathrm{y}$ cuenta con una Disposición Adicional Tercera ${ }^{28}$, específica para las Ciudad, que resalta su inclusión dentro del sistema peculiar de fuentes aplicable a sus funcionarios públicos propios, y por tanto a su Policía local, reconociéndole potestad reglamentaria en materia de función pública. La incorporación del Estatuto Básico del Empleado Público al grupo normativo regulador del Cuerpo policial melillense ha sido avalada por, entre otras, la Sentencia $n^{\circ} 234 / 2011$ del Juzgado Contencioso-Administrativo $\mathrm{n}^{\circ} 2$ de Melilla al disponer en su fundamento jurídico cuarto que:

24 Artículo 3.2 del TREBEP: "Los Cuerpos de Policía Local se rigen también por este Estatuto..........., excepto en lo establecido para ellos en la Ley Orgánica 2/1986, de 13 de marzo, de Fuerzas y Cuerpos de Seguridad".

25 Artículo 4 del TREBEP: "Las disposiciones de este Estatuto sólo se aplicarán directamente cuando asi lo disponga su legislación especifica al siguiente personal: e) Personal de las Fuerzas y Cuerpos de Seguridad".

26 Artículo 2.5 del TREBEP: "El presente Estatuto tiene carácter supletorio para todo el personal de las Administraciones Públicas no incluido en su ámbito de aplicación”.

27 Artículo 2.1 del TREBEP: "Este Estatuto se aplica al personal funcionario y en lo que proceda al personal laboral al servicio de las siguientes Administraciones Públicas. b) Las Administraciones de las comunidades autónomas y de las ciudades de Ceuta y Melilla".

28 Disposición Adicional Tercera del TREBEP: "1. Los funcionarios públicos propios de las administraciones de las ciudades de Ceuta y Melilla se rigen por lo dispuesto en este Estatuto, por las normas de carácter reglamentario que en su desarrollo puedan aprobar sus Asambleas en el marco de sus estatutos respectivos, por las normas que en su desarrollo pueda dictar el Estado y por la Ley de Función Pública de la Administración General del Estado.2 .En el marco de lo previsto en el número anterior, las Asambleas de Ceuta y Melilla tendrán, además, las siguientes funciones: a) El establecimiento, modificación y supresión de Escalas, Subescalas y clases de funcionarios, y la clasificación de los mismos. b) La aprobación de las plantillas y relaciones de puestos de trabajo. c) La regulación del procedimiento de provisión de puestos directivos así como su régimen de permanencia y cese. d) La determinación de las faltas y sanciones disciplinarias leves". 
"El Cuerpo de la Policía Local de la CAM se rige en cuanto a su régimen estatutario dada su condición funcionarial por el Estatuto Básico del Empleado Público aprobado por la Ley 7/2007, de 12 de abril de 2007, existiendo especial referencia a los funcionarios públicos melillenses en su Disposición Adicional $4^{\mathrm{a}}$, y dada su condición policial por la Ley Orgánica 2/1986, de 13 de marzo, de Fuerzas y Cuerpos de Seguridad del Estado (artículo 3.2 EBEP), así como por el Reglamento de la Policía Local de la Ciudad de Melilla publicado en el BOME núm.4648, de 2 de octubre de 2009".

Por todo ello, con respeto absoluto a los preceptos específicos de Policía Local de la LOFCS, será aplicable la legislación estatal de régimen local y la de función pública. Además, y teniendo en cuenta que las competencias que puede asumir la Policía local de Melilla son numerosísimas a tenor del artículo 53 de la LOFCS y el Título II del E.A, la normativa aplicable no puede restringirse a la que regula su organización, funciones y régimen estatutario, teniendo que añadirse la normativa sectorial de la legislación general del estado a la que se remite el Estatuto de Autonomía en sus artículos 21 y 22 del EA al determinar el alcance de las competencias que goza la Ciudad y que tendrán su incidencia correspondiente sobre la Policía Local en cuanto el ejercicio de sus actuaciones $^{29}$ estén relacionadas con alguna de esas materias, a las que habrá que añadir las que corresponden a los Ayuntamientos o Diputaciones en virtud del artículo 25 del $\mathrm{EA}^{30}$.

En un último escalón, el sistema de fuentes señalado reconoce la potestad de reglamentación de la Ciudad Autónoma en materia de policía local ${ }^{31}$, debiendo respetarse, como hemos visto, la legislación estatal de aplicación, representadas fundamentalmente por la LOFCS $^{32}$

29 La actuación policial en estos ámbitos suele dirigirse hacia la actividad de inspección y denuncia con el consecuente ejercicio de la potestad sancionadora de la Administración.

3o Artículo 25 del E.A: "La ciudad de Melilla ejercerá además todas las competencias que la legislación estatal atribuye a los Ayuntamientos así como las que actualmente ejerce de las Diputaciones provinciales y la que en el futuro puedan atribuirse a éstas por Ley del Estado".

31 Artículo 52.1 de la LOFCS, Artículo 21.1.24 de la Ley Orgánica 2/1995 que aprueba el Estatuto de Autonomía de Melilla y la Disposición Adicional Tercera del TREBEP.

32 Artículo 39 de la LOFCS: "Corresponde a las Comunidades Autónomas, de conformidad con la presente Ley y con la de Bases de Régimen Local, coordinar a la actuación de las Policías Locales en el ámbito territorial de la Comunidad, mediante el ejercicio de las siguientes funciones: a) Establecimientos de las normas-marco a las que habrán de ajustarse los Reglamentos de Policías Locales, de conformidad con lo dispuesto en la presente Ley y en la de Bases de Régimen Local. b) Establecer o propiciar, según los casos, la 
por la condición de miembros de las Fuerzas y Cuerpos de Seguridad, la legislación estatal de régimen local y la legislación estatal de función pública, pudiendo completar y complementar la regulación existente.

A pesar del numeroso conjunto normativo regulador de procedencia estatal, la potestad normativa de la Ciudad en el ámbito de la Policía local goza de un mayor alcance que el del resto de municipios al no encontrarse sujeta a las correspondientes normas marcos que dictan las diferentes Comunidades Autónomas en virtud de sus facultades de coordinación constitucionalmente asumidas y recogidas en el artículo 39 de la LOFCS y que han supuesto una limitación de las potestades innovatorias que podían asumir las distintas corporaciones locales a través de sus reglamentos municipales. Esta limitación de la autonomía normativa de los municipios no es extensiva a las Ciudades con Estatuto de Autonomía que al no encontrarse integradas territorialmente, como hemos visto, en una CCAA gozan de una capacidad regulatoria en materia de policía local no restringida por estas disposiciones "armonizadoras" de las normas-marco autonómicas.

De hecho, el artículo 21.2 de la Ley Orgánica 2/1995, de 13 de marzo, del Estatuto de Autonomía de Melilla atribuye expresamente a nuestra Ciudad Autónoma "las facultades de administración, inspección y sanción y, en los términos que establezca la legislación general del Estado, la potestad normativa reglamentaria" de aquellas materias reguladas en el propio artículo 21.1, entre las que se incluye la "vigilancia y protección de sus edificios e instalaciones. Policía Local en los términos que establezca la Ley a que se refiere el artículo 149.1.29 de la Constitución" Al ubicar el Estatuto la potestad reglamentaria en materia de policía local en el artículo 21, y diferenciarlo de la facultad normativa de organización de servicios de carácter interno de las materias recogidas en el artículo 22, se reconoce un alcance de la potestad reglamentaria de las primeras, entre ellas la de policía local, que van más allá de una mera organización o estructuración del servicio de carácter interno como ha manifestado la doctrina científica a través del profesor Hernández Lafuente (1995, p. 252-253).

homogeneización de los distintos Cuerpos de Policías Locales, en materia de medios técnicos para aumentar la eficacia y colaboración de éstos, de uniformes y de retribuciones. c) Fijar los criterios de selección, formación, promoción y movilidad de las Policias Locales, determinando los distintos niveles educativos exigibles para cada categoria, sin que, en ningún caso, el nivel pueda ser inferior a graduado escolar. d) Coordinar la formación profesional de las Policías Locales, mediante la creación de Escuelas de Formación de Mandos y de Formación Básica". 
"Independientemente de estas dudas teóricas (se refiere a la relación ley estatal-reglamento de las ciudades) pueden presentarse problemas en la práctica. Dependiendo del contenido de la ley estatal, de la existencia o no de reglamento estatal, o de si se trata de legislación básica que las Comunidades Autónomas desarrollen, y en consecuencia el Estado sólo establezca las bases, el posible contenido y límites de los reglamentos será muy variado. No se deduce del texto al margen que se pretende otorgar respecto de las materias señaladas en el artículo 21, situándose este ámbito de desarrollo reglamentario por debajo del amplio que ostentan las leyes autonómicas para el desarrollo de las bases estatales, pero superando el margen de la potestad normativa reglamentaria para la organización de los correspondientes servicios, que establece el apartado 2 del artículo 22"

En la misma línea se pronunció Castellá Andreu y Pons Parera (1995-1996).

"Sin duda, la naturaleza y alcance de esta potestad reglamentaria de las dos Ciudades Autónomas constituye uno de los aspectos más singulares introducidos por los Estatutos de Autonomía de 1995. Éstos no precisan el margen propio de dichas normas reglamentarias, los cuales sólo vienen enmarcadas por los términos que establezca la legislación general del estado. Esta fórmula permite reconocerán ámbito de actuación muy amplio al reglamento autonómico, que puede entrar a regular materias recogidas en el artículo 21 sin desarrollar estrictamente una ley previa. Se origina, así, un tipo nuevo de articulación competencial ...en el que será el reglamento la norma primera que concreta la legislación estatal, ...”.

Además, el TREBEP incorpora una Disposición Adicional Tercera, por la cual Melilla consigue alcanzar capacidad, no establecida en su Estatuto de Autonomía, de reglamentar en materia de función pública contando con margen propio para regular opciones particulares de configuración de sus recursos humanos lo que en materia de policía local, se va a revelar en el contenido de su Reglamento, máxime cuando la propia Disposición del TREBEP respecto a la función pública de la Ciudad atenúa en determinadas materias el mandato constitucional de reserva de ley que establece para el régimen estatutario de los funcionarios el artículo $103.3^{33}$ de la $\mathrm{CE}$, debiendo entenderse que esta reserva se re-

$33 \quad$ La ley regulará el estatuto de los funcionarios públicos, el acceso a la función pública de acuerdo con los principios de mérito y capacidad, las peculiaridades del ejercicio de su derecho a sindicación, el sistema de incompatibilidades y las garantías para la imparcialidad en el ejercicio de sus funciones. 
fiere al régimen estatutario esencial de los funcionarios, pero sin impedir que las disposiciones reglamentarias puedan, cuando así lo requiera la Ley, colaborar con ella para complementar o particularizar, en aspectos instrumentales y con la debida sujeción, la ordenación legal de la materia reservada.

Estamos, pues, ante una potestad reglamentaria de la Ciudad que en materia de policía local constituye un poder normativo autónomo relacionado con la legislación estatal a través del principio de vinculación negativa, gozando de una fuerza innovadora que presenta unas singularidades determinantes de manera que aunque tengan sus normas habilitantes en la LOFCS y en la legislación estatal de régimen local y de función pública, el Reglamento policial de la Ciudad de Melilla no es en realidad una norma dictada en desarrollo de las anteriores sino una disposición general que plasma la potestad de la Ciudad de otorgarse normas y autoorganizarse en esta materia.

Con las premisas anteriores la Asamblea de Melilla en sesión de treinta de septiembre de 2009, aprobó definitivamente el Reglamento de la Policía Local de Melilla (BOME n 4648 de 2 de octubre de 2009) (B4 $^{34}$ (en adelante RPLM). A diferencia de los reglamentos ejecutivos de las leyes, que deben seguir estrictamente el espíritu y la letra de la que traen causa, el Reglamento policial de la Ciudad se mueve en otro ámbito donde la legislación estatal no sirve sino como marco para acotar o deslindar, y por tanto sus preceptos sólo podrán ser considerados ilegales si contradijeran frontalmente la legislación estatal, pues si admitieran una interpretación conforme a ella, habría de concluirse a favor de su validez.

Avalando la postura doctrinal mantenida, el Tribunal Superior de Justicia de Andalucía ${ }^{35}$, Sala de lo Contencioso Administrativo, en su Sentencia de 25 de febrero de 2011, respecto al Reglamento de Policía Local de Melilla dispuso que:

"Entrando a conocer del primero de los motivos alegados, por el que, según quedó dicho, se discute la legalidad en su conjunto del Reglamento impugnado, por entender la parte recurrente que al no haberse observado el trámite de interesar informe preceptivo del Consejo de Estado, se incurrió en vicio de nulidad, aún cuando es lo cierto que en el suplico de

\footnotetext{
34 Modificaciones posteriores en BOME $n^{\circ} 4793$ de 22 de febrero de 2011 y BOME $n^{\circ}$ 5472 de 25 de agosto de 2017.

STSF 560/2011 (Rec. 1126/2009
} 
la demanda, la recurrente no formula petición al respecto, al constar en los fundamentos de derecho una invocación concreta del motivo, hay que entender que ello es una simple omisión formal que como tal no supone abandono o renuncia de la pretensión anulatoria sustentada en él, lo que hace que el Tribunal deba entrar a su conocimiento y en este sentido el recurso no puede prosperar pues sin desconocer que según dispone el artículo 22.3 de la L.O. 3/80 (LA LEY 794/1980) reguladora del Consejo de Estado, la Comisión permanente debe ser consultada en Reglamentos o Disposiciones de carácter general que se dicten en ejecución de leyes, así como sus modificaciones, al ser lo cierto que el reglamento que se impugna, no se ha dictado en desarrollo de la ley 7/86 de Fuerzas y Cuerpos de Seguridad ni de la Ley 7/07 del Estatuto Básico del Empleado Público, ni de la Legislación Estatal de Régimen Local, cuestión distinta a que deba respetar en su contenido lo preceptuado en ellas, sino que ha sido dictado en base a lo dispuesto en el artículo 4 a de la Ley de Bases de Régimen Local, en relación con el R.D.L. 781/86 (LA LEY 968/1986) , y que por lo que respecta al supuesto singular de la ciudad no puede calificarse como un reglamento dictado como simple ejecución de una ley estatal sino que el mismo, so pena de relegar a un segundo plano la autonomía de dicha ciudad, ha sido dictado por un órgano que a tales efectos ha de tenerse como equivalente a las asambleas legislativas de estas CCAA, de manera que si bien con carácter formal es el reglamentario, hay que entender que en cuarto a la capacidad legislativa ha sido adoptado como si de una ley se tratase, siendo asi que, al ser el grado de vinculación de la normativa estatal es solamente negativo, y no positivo, como se dijo anteriormente la única exigencia para su regulación es de indole material, en el sentido de respeto a las leyes estatales en cuanto a la materia de su competencia, y no formal en cuanto a que deba de seguirse los trámites propios de un reglamento ejecutivo de una ley."

El RPLM manifiesta la capacidad de autoordenación de la Ciudad y se inserta en el sistema normativo del estatuto de los policías locales melillenses completándolo y complementándolo, innovando aspectos esenciales de la organización y funcionamiento del Cuerpo y pretendiendo dar respuesta a diferentes facetas de la vida policial. Es un texto normativo que sólo debe encontrar en la legislación estatal aplicable límites negativos, contando con una fuerza innovadora como expresión de la autonomía de la Ciudad todo ello en los términos de la legislación estatal aplicable que va a servir de parámetro controlador o límite de la legalidad del texto imponiendo el marco y los términos que puede alcanzar la potestad reglamentaria. 
Por tanto, la competencia de la Ciudad en materia de Policía Local no se reduce a la mera gestión del Cuerpo, sino que su autonomía reforzada derivada de su propio Estatuto de Autonomía y confirmada por la legislación básica de función pública le otorga capacidad efectiva de regular y adoptar decisiones propias dentro de su marco normativo de aplicación con un mayor alcance que el del resto de municipios.

El RPLM se estructura actualmente en siete Títulos, ciento dieciséis artículos, tres Disposiciones Transitorias y dos Disposiciones Finales de las cuales la primera faculta al Consejo de Gobierno para, al amparo de lo establecido en el artículo 17 apartados segundo ${ }^{36}$ y tercero $^{37}$ del Estatuto de Autonomía, desarrollarlo reglamentariamente lo que supone otro plus de autonomía respecto a las Juntas de gobierno de los municipios que carecen de potestad normativa en este ámbito.

El RPLM, además de intentar resumir escuetamente en su artículo 4 el complejo régimen jurídico del Cuerpo ${ }^{38}$, asume una trascendental y novedosa aportación al ordenamiento de la Policía en materias, entre otras, cómo la denominación de las categorías profesionales, las funciones específicas de las escalas y categorías, su estructura y organización, el sistema de provisión del puesto de Jefe del Cuerpo, requisitos y formas del saludo como manifestación externa de educación cívica, respeto y disciplina, medios tácticos, escalafón, segunda actividad, la entrega, custodia y uso del arma de fuego, la defensa jurídica, formación, distinciones y honores de sus miembros, el reconocimiento y respeto de los derechos personales y profesionales con las obligadas limitaciones por razón de las especiales características de la función asumida, así como una relación de deberes, de manera que exista el necesario equilibrio para que la razón de servicio público y los intereses profesionales del colectivo policial de la Ciudad sean compatibles.

36 Artículo 17.2 del E.A: "El Consejo de Gobierno podrá desarrollar reglamentariamente las normas aprobadas por la Asamblea en los casos en que aquéllas lo autoricen expresamente".

37 Artículo 17.3 del E.A: "En todo caso, el Consejo de Gobierno tendrá la competencia para desarrollar las normas dictadas por la Asamblea sobre organización y funcionamiento de los servicios administrativos de la ciudad de Melilla".

38 Artículo 4 del RPLM: "La Policía Local de la Ciudad Autónoma de Melilla se regirá por lo dispuesto para ellos en la L.O. 2/1.986, de 13 de marzo, de Fuerzas y Cuerpos de Seguridad, por el RDL 5/2015, de 30 de octubre, por el que se aprueba el Texto Refundido de la Ley del Estatuto Básico del Empleado Público, la legislación estatal que resulte de aplicación, el Reglamento de la Policía Local de Melilla y demás normativa de la Ciudad Autónoma". 
En definitiva en el ámbito normativo de la Ciudad se confirma la difícil configuración del sistema de fuentes de régimen jurídico de la Policía Local como ya concretó el propio Tribunal Constitucional en su Sentencia de 21 de enero de $1993^{39}$ definiendo el ordenamiento regulador de estos Cuerpos como "un conjunto a veces muy complejo de remisiones en cadena y hasta de reenvíos mutuos, a su vez con salvedades o excepciones que enturbian en alguna ocasión el entendimiento de la voluntas legis...".

La Policía Local melillense se encuentra sometida, pues, a un conjunto amplísimo de normas de distinto valor y procedencia, un régimen jurídico heterogéneo que constituye su marco de actuación y que requiere un estudio más extenso que analice con cierto detalle los referentes jurídicos que hemos mencionado. Examen más profundo que no podrá obviar la necesidad de modificar la LOFCS que al aprobarse en el año 1986, nueve años antes de la aprobación del Estatuto de Autonomía de Melilla, no incluye expresamente, más allá de la posibilidad de contar con los llamados Agentes de Movilidad $^{40}$, las particularidades de Ceuta y Melilla debiendo reconocerles, al menos, el carácter de Administraciones Públicas que van a colaborar en el mantenimiento de la Seguridad Pública en los términos que establezcan sus respectivos Estatutos (artículo 21.124 del E.A) y en el marco de la propia LOFCS. El reconocimiento expreso en la LOFCS de las Ciudades con Estatuto de Autonomía debe imponerse por razones de coherencia con el régimen de autonomía singular de las mismas que se evidencia, entre otros muchos aspectos, especialmente en el régimen jurídico de su Policía Local.

\footnotetext{
39 STC 25/1993.

40 La Disposición final primera de la Ley Orgánica 9/2013, de 20 de diciembre, de control de la deuda comercial en el sector público (BOE núm. 305 de 21 de diciembre de 2013) ha modificado el primer párrafo del artículo 53.3 de la Ley Orgánica 2/1986, de 13 de marzo, de Fuerzas y Cuerpos de Seguridad del Estado quedando redactado en los siguientes términos: "En los municipios de gran población y en las Ciudades con Estatuto de Autonomía podrá asignarse, por el Pleno de la Corporación o por sus respectivas Asambleas, al ejercicio exclusivo de las funciones previstas en el párrafo b) del apartado 1 a parte de los funcionarios pertenecientes a las mismas, que tendrán la consideración de agentes de la autoridad, subordinados a los miembros de los respectivos Cuerpos de Policia Local, sin integrarse en las Fuerzas y Cuerpos de Seguridad y de manera que ello no comporte un incremento en el número de efectivos ni en los costes de personal».
} 


\section{Bibliografía}

CASTELL ARTECHE, (1989). El marco normativo de los cuerpos de seguridad pública desde la vertiente competencial. Libro homenaje al profesor José Luis Villar Palasí. Editorial Civitas.

CASTELLÁ ANDREU, Josep María y PONS PARERA, Eva, (1995-1996). Los estatutos de autonomía de Ceuta y Melilla. Informe Pi i Sunyer sobre comunidades autónomas 1995-1996. Edit fundación Carles Pi i Sunyer d'Estudis Autonomics i Locals.

HERNÁNDEZ LAFUENTE, Adolfo (1995). Estatutos de autonomía para Ceuta y Melilla. Málaga: Algazara.

PÉREZ LUQUE, (1999). La estructura de personal de las corporaciones locales. Editorial Comares.

VILLAGÓMEZ CEBRIÁN, (1997). Las fuerzas y cuerpos de seguridad: del orden público a la seguridad ciudadana. Edición Ara Solís. Xunta de Galicia.

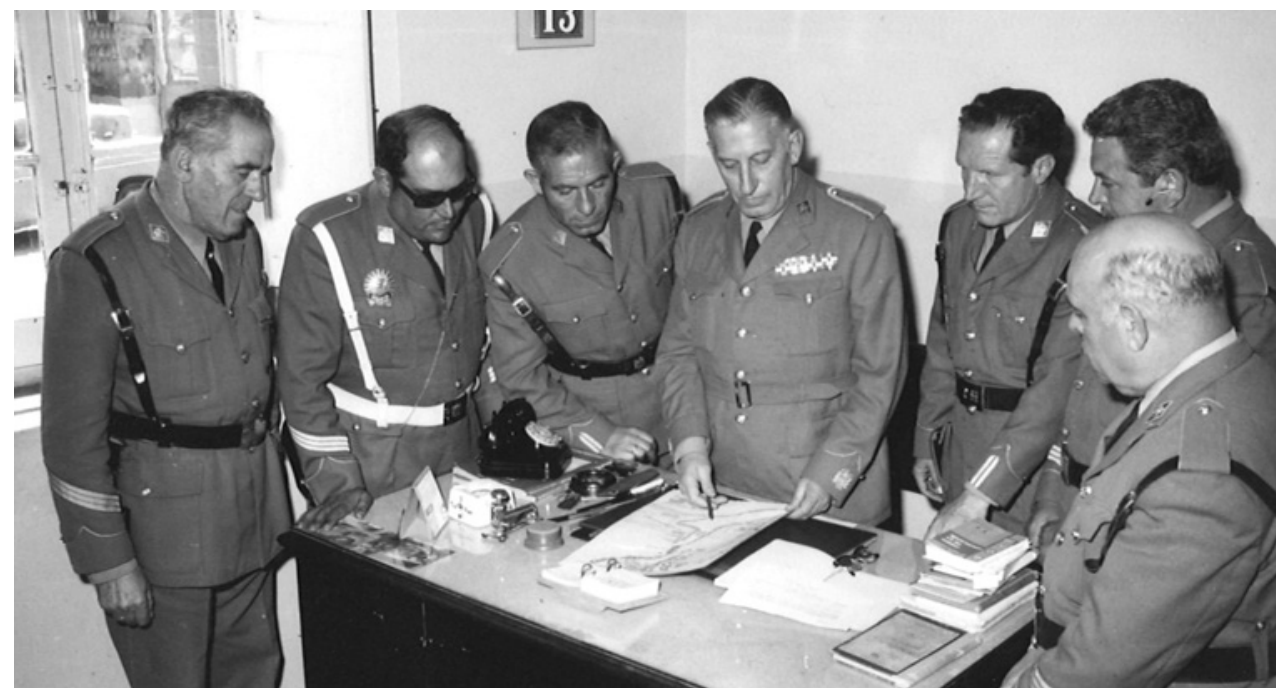

Fig.1. Reunión de mandos de la Policía Municipal 


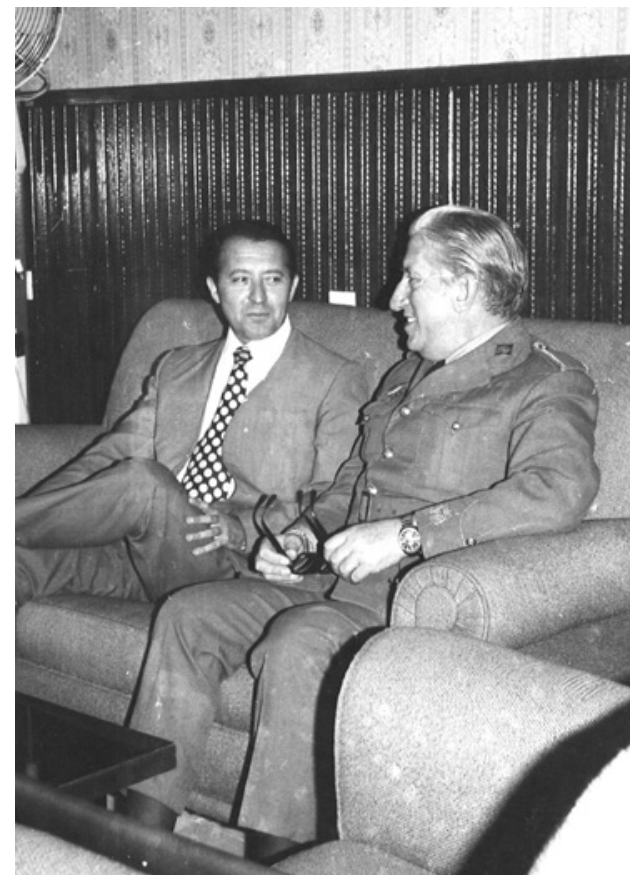

Fig.2 Encuentro con autoridades civiles

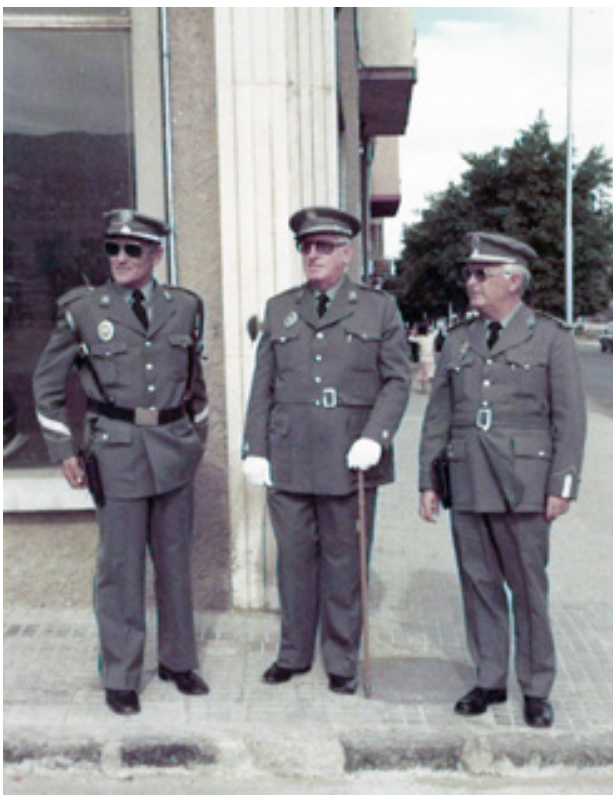

Fig.3 De izquierda a derecha, Sargento Ginés, fefe de Policía Alemany y Cabo González

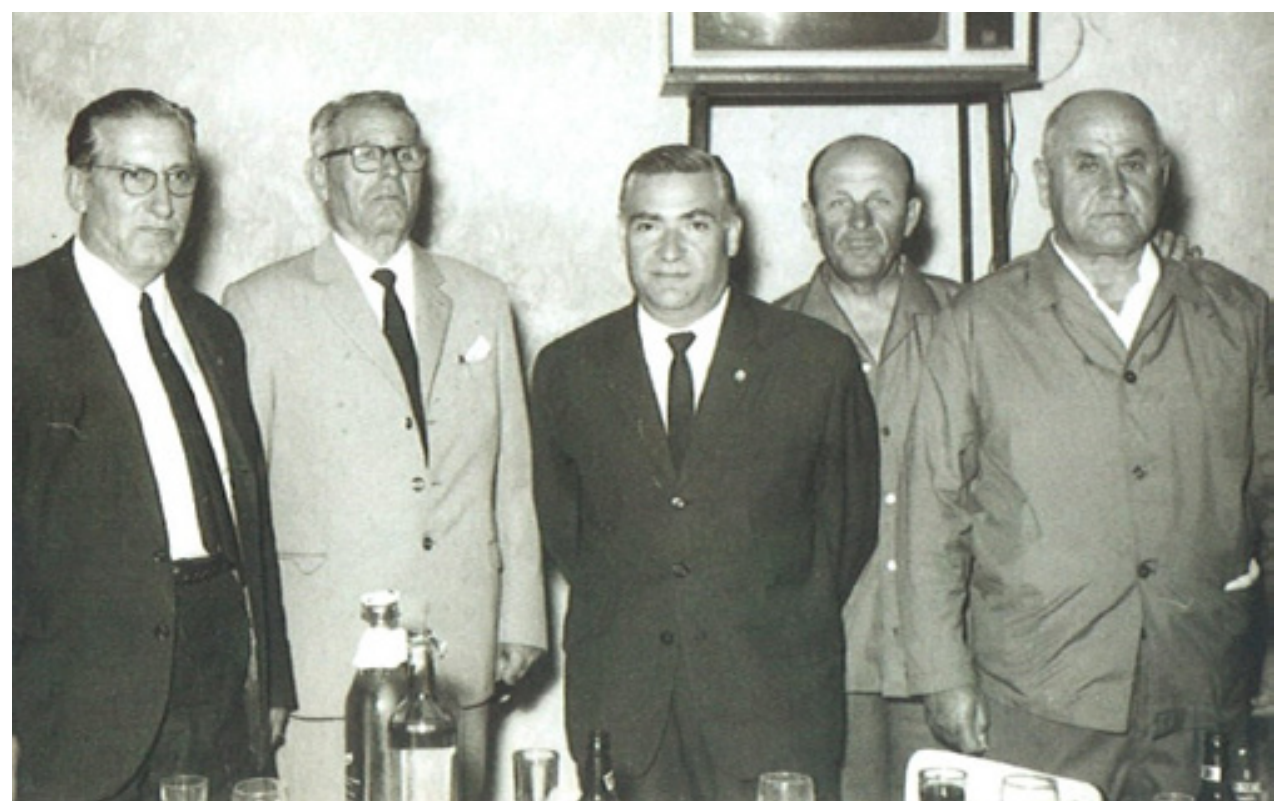

Fig.4. Acto de jubilación de la Policía Municipal 